\title{
Short-term efficacy and safety of low-intensity extracorporeal shock wave therapy in erectile dysfunction: a systematic review and meta-analysis
}

Zi-jun Zou ${ }^{1}$, Liang-you Tang ${ }^{1}$, Zhi-hong Liu ${ }^{1}$, Jia-yu Liang ${ }^{1}$, Ruo-chen Zhang ${ }^{1}$, Yu-jie Wang ${ }^{1}$, Yong-quan Tang ${ }^{1}$, Rui Gao ${ }^{2}$, Yi-ping Lu ${ }^{1}$

${ }^{1}$ Department of Urology, Institute of Urology, West China Hospital, Sichuan University, Chengdu, Sichuan, P.R. China; ${ }^{2}$ Department of Urology, the First Affiliated Hospital of Fujian Medical University, Fuzhou, Fujian, P.R. China

\section{ABSTRACT}

Aim: The role of low-intensity extracorporeal shock wave therapy (LI-ESWT) in erectile dysfunction (ED) is not clearly determined. The purpose of this study is to investigate the short-term efficacy and safety of LI-ESWT for ED patients.

Materials and Methods: Relevant studies were searched in Medline, Embase, Cochrane Library, China National Knowledge Infrastructure (CNKI), WANFANG and VIP databases. Effective rate in terms of International Index of Erectile Function-Erectile Function Domain (IIEF-EF) and Erectile Hardness Score (EHS) at about 1month after LI-ESWT was extracted from eligible studies for meta-analysis to calculate risk ratio (RR) of effective treatment in ED patients treated by LI-ESWT compared to those receiving sham-treatment.

Results: Overall fifteen studies were included in the review, of which four randomized controlled trials (RCTs) were for meta-analysis. Effective treatment was 8.31 [95\% confidence interval (CI): 3.88-17.78] times more effective in the LI-ESWT group $(n=176)$ than in the sham-treatment group $(n=101)$ at about 1 month after the intervention in terms of EHS, while it was 2.50 (95\% CI: 0.74-8.45) times more in the treatment group $(n=121)$ than in the control group $(n=89)$ in terms of IIEF-EF. Nine-week protocol with energy density of $0.09 \mathrm{~mJ} / \mathrm{mm}^{2}$ and 1500 pluses seemed to have better therapeutic effect than five-week protocol. No significant adverse event was reported.

Conclusion: LI-ESWT, as a noninvasive treatment, has potential short-term therapeutic effect on patients with organic ED irrespective of sensitivity to PDE5is. Owing to the limited number and quality of the studies, more large-scale, well-designed and longterm follow-up time studies are needed to confirm our analysis.

\section{ARTICLE INFO}

\section{Keywords:}

Erectile Dysfunction;

Therapeutics; Meta-Analysis as

Topic

Int Braz J Urol. 2017; 43: 805-21

Submitted for publication:

April 26, 2016

Accepted after revision:

January 22, 2017

Published as Ahead of Print:

March 21, 2017

\section{INTRODUCTION}

Erectile dysfunction (ED) is a common male sexual dysfunction and oral phosphodiesterase type 5 inhibitor (PDE5i) is a first-line therapy (1). Although ameliorating erectile function
(EF) significantly, PDE5is are not curative approaches and patients have to plan sexual activity with the aid of medication. In addition, a part of ED patients poorly respond to PDE5is and need to turn to invasive treatments such as intra-cavernosal injection of vasoactive agents 
and surgical implantation of penile prostheses. Therefore, a novel treatment that improves EF in a noninvasive and enduring manner is required.

Shockwave is characterized by acoustic wave generating pressure impulses. It has been used widely in the field of medicine, where the role of shockwave therapy varies with the level of energy intensity (2). Different from highand medium-intensity shockwave with focused mechanical destructive and anti-inflammatory nature, low-intensity extracorporeal shock wave therapy (LI-ESWT) probably has angiogenic property based on resultant cell membrane microtrauma and mechanical stress that are associated with the release of angiogenic factors (3) and recruitment of circulating endothelial progenitor cells (4). Therefore, LI-ESWT has been used for vasculogenic disease containing peripheral artery disease (5), chronic wounds (6), and cardiac ischemic diseases (7).

Based on the potential stimulation of angiogenesis and local vascularization (8), LI-ESWT was also used for vasculogenic ED and had considerable effectiveness in terms of sexual performance, penile blood flow and endothelial function (9-11). It will hopefully make up the defects in the treatment of ED given that 1) the potential property of altering spontaneous erectile function in an enduring and pathophysiological way (9); 2) reversing insensitivity to PDE5is (11). Meanwhile, penile LI-ESWT was proved to be safe during and after the treatment in the pilot studies (9-11).

Although underlying mechanism is still under investigation, LI-ESWT has been listed in the chapter of first-line therapy since 2013 European Association of Urology (EAU) guidelines on male sexual dysfunction (1), supported by a series of prospective trials containing randomized controlled trials (RCTs) (9-11). Nevertheless, defined recommendation cannot be given because current evidences are relatively limited. Recently, two systematic reviews and meta-analyses $(12,13)$ on the topic were published. However, the result of the study by Lu et al. (12) was less convincing because significant heterogeneity existed among included studies with ED patients originating from different pathology, and the evidence level of Angulo's study (13) was lowe- red by including single-arm trials. Therefore, a systematic review and meta-analysis focusing on RCTs regarding LI-ESWT for organic ED without Peyronie's disease (PD) and chronic pelvic pain (CPP) is essential.

\section{MATERIALS AND METHODS}

The systematic review and meta-analysis was performed following PRISMA criteria (14).

\section{Criteria for study inclusion/exclusion}

Studies, which contained RCT, single-arm trial and respective study, reporting LI-ESWT in the management of ED patients without PD and CPP, were included for this systematic review. If data regarding effective and/or complication rate could be extracted, those included RCTs were further performed for meta-analysis. In addition to eligible original articles, reviews in the field were also identified for further searching of reference lists to ensure the completeness of the literature search. Case reports, letters to the editor, conference abstract, comment and basic studies were excluded.

Two authors reviewed the included articles independently. Disagreements were resolved by discussion and consensus. Duplicate publications were excluded, and when different literatures discussed a same cohort, the most informative one was used for further analysis.

\section{Search strategy}

Two authors independently searched Medline, Embase, Cochrane library and Chinese medical electronic databases including China National Knowledge Infrastructure (CNKI), WANFANG and VIP by using one of "shockwave" and "shock wave" combined with one of "erectile dysfunction" and "ED" as a search term with overall 4 combinations. English and Chinese literatures between January 2010 and December 2015 were included. The reference lists of eligible studies and relevant reviews were searched in case of possible missing articles.

Assessment of risk of bias in included studies Risk of bias in the RCT was assessed according to the Cochrane Collaboration's tool 
for assessing risk of bias (15), which addresses sequence generation, allocation concealment, blinding, handling of incomplete data, and selective reporting. The quality of other studies was assessed by the Methodological Index for Non-randomized Studies (MINORS) (16) and global ideal score is 16 points for non-comparative study.

\section{Data extraction}

Data extraction was done by two authors independently, and disagreements were resolved by discussion. Titles and abstracts were used to screen for initial study inclusion. Full-text review was carried out on the remaining papers that matched inclusion/exclusion criteria. The same reviewers performed all data extraction including study characteristics and outcome data. A data-extraction form was used with variables containing author, publication year, type of study, country, LI-ESWT protocol, ED type, previous sensitivity of PDE5i, endpoints, and outcomes.

In the meta-analysis, effect size (ES) was risk ratio (RR) of effective treatment in ED patients receiving LI-ESWT and sham treatment. International Index of Erectile Function-Erectile Function Domain (IIEF-EF) score and Erectile Hardness Score (EHS) were validated and most widely used in clinical trials to evaluate erectile function. The numbers of total participants and effective ones measured with them were extracted from included literatures. Short-term effective treatment was defined as 5-point or greater improvement in the IIEF-EF between baseline and score at about 1 month after LI-ESWT or an increase in EHS from 2 or less at baseline to 3 or more at about 1 month after the intervention. The definitions were accepted because most participants and studies could be included. Adverse event outcome was also summarized and analyzed.

\section{Statistical analysis}

Random effects model was selected for the calculation of RR based on acknowledging heterogeneities in our samples with several protocols of LI-ESWT and populations with different sensitivity of PDE5is. A chi-squared test was conducted for heterogeneity evaluation and $p$ value less than 0.05 was considered to be statistically significant. $\mathrm{I}^{2}$ index was used to quantify between-study heterogeneity's contribution to overall heterogeneity. Funnel plot was conducted for evaluation of publication bias. Sensitivity analysis was conducted to explore the heterogeneity via excluding every study one by one. Subgroup analysis according to different protocols, energy densities and doses of LI-ESWT, the consistency of risk factors between the treatment and control group, and sensitivity to PDE5is, was conducted. Statistical calculation was conducted using Review Manager (version 5.3) software.

\section{RESULTS}

\section{Literature search results}

The search process is shown in Figure-1. The first search yielded 572 potentially relevant studies, of which 386 were irrelevant and were excluded after reviewing their titles. Abstracts of the remaining 186 studies were considered for detailed evaluation. One hundred and sixty one studies were excluded in that stage due to reduplicate cohorts, and being letter to the editor, case report, conference abstract and comment. No more eligible articles were found in search of the reference lists of 10 relevant reviews and the 15 original literatures.

Finally, 15 original articles (9-11, 1728) were included in the systematic review after full-text evaluation. Table-1 shows the characteristics of the eligible studies with 6 RCTs (10, $17,18,21,25,28)$ and 9 prospective, single-arm trials $(9,11,19,20,22-24,26,27)$. There was a study (27) about ED secondary to nerve-sparing prostatectomy, while the other studies focused on organic ED that was mainly considered to be vasculogenic. Although the protocol, device, energy density and dose of LI-ESWT were not uniform, all treatments had positive effects on ED in the studies. The details of the methods were summarized in Table-2. A RCT from China (21) compared the efficacy of LI-ESWT and va- 
Figure 1 - Flow diagram outlining search results and final included and excluded studies.




cuum erectile device for ED. With two RCTs (18, 21) with lack of sufficient data, overall 4 RCTs $(10,17,25,28)$ were included for quantitative synthesis.

\section{The quality of the included studies}

The risks of bias in two RCTs were considered to be high owing to high dropout rate (25) and not performing blind method in performance (21). Three RCTs $(10,17,28)$ had unclear risks of bias without details of randomization and/or blind method, and only one RCT was evaluated as being low risk of bias (18). According to MINORS (16), all non-comparative studies were 12 scores with lack of information of blind evaluation of endpoints and prospective calculation of the study size.

Evaluation of the effect of LI-ESWT on ED in terms of IIEF-EF and EHS, and its safety

Three RCTs $(10,17,28)$ comparing IIEF-EF-based effective rate (ER) in patients receiving LI-ESWT $(n=121)$ and sham treatment $(n=89)$ were included for the calculation of RR. Effective treatment was 2.50 [95\% confidence interval (CI): 0.74-8.54] times higher in the LI-ESWT group than in the sham-controlled group at about 1 month after last session and heterogeneity may be substantial ( $\left.p=0.02 ; \mathrm{I}^{2}: 75 \%\right)$. In terms of EHS, including 4 RCTs $(10,17,25,28)$ of 277 patients, RR is 8.31 with 95\% CI ranging from 3.88 to $17.78\left(\mathrm{p}=0.42 ; \mathrm{I}^{2}: 0 \%\right)$, as seen in Figure-2. Funnel plot was asymmetrical showing publication bias. Sensitivity analysis in IIEF-EF revealed that the study by Olsen et al. (17) influenced heterogeneity significantly and when the study was excluded, $\mathrm{I}^{2}$ and $\mathrm{p}$ value was $24 \%$ and 0.25 , respectively, while RR was 4.40 (95\%CI: 1.18-16.38). Sensitivity analysis indicated that the result was stable in EHS.

In subgroup analysis, as seen in Figures 3 and 4, it was showed that in EHS 9-week protocol with energy density of $0.09 \mathrm{~mJ} / \mathrm{mm}^{2}$ and 1500 pluses (RR: 22.59; 95\% CI: 4.65-109.79) was probably more effective than 5 -week protocol with energy density of $0.15 \mathrm{~mJ} / \mathrm{mm}^{2}$ and 3000 pulses (RR: 6.14; 95\% CI: 2.58-14.64) based on possibly substantial between-group heterogeneity, although the difference did not reach statistical significance. Similar result was observed in IIEF-EF with RR of 4.40 (95\% CI: 1.18-16.38) in 9-week group and 1.16 (95\% CI: $0.71-1.90)$ in 5-week group with the $p$ value of subgroup differences being 0.06. In our analysis, LI-ESWT for PDE5i non-responders was more likely to contribute to effective treatment (RR: 15.50, 95\% CI: 0.98-245.34, in IIEF-EF; RR: 20.50, 95\% CI: 1.31-320.94, in EHS), than for responders (RR: 1.81, 95\% CI: 0.64-5.11, in IIEF-EF; RR: 8.58, 95\% CI: 3.17-23.23, in EHS), but difference was not statistically significant. To explain whether the consistency of risk factors of ED, such as age, cardiac disease, diabetes mellitus (DM), et al., between treatment and control group influenced analysis outcome, we summarized the baseline characteristics of study population from the 4 RCTs (Table-3) and performed subgroup analysis according to consistency of risk factors. It was found that the outcome of studies with consistent risk factor was lower (RR: 7.41; 95\% CI: 3.36-16.38), than that with inconsistent risk factors (RR: 32.16; 95\% CI: 2.09-495.35), but it did not reach statistical significance either $(p=0.31)$.

There was no reported severe complication, which needed medical intervention.

\section{DISCUSSION}

Since 2010 when Vardi et al. (9) published the first literature on LI-ESWT for ED, most of published clinical studies $(9-11,17-28)$ on the topic have favored the modality with the ability of ameliorating patient's EF. It has been written in the EAU guideline as a potential first-line therapy for ED since 2013, although detailed recommendation has not been given since then. On the basis of current literatures, our metaanalysis also suggested that penile LI-ESWT probably represents an effective approach in the treatment of ED, when evaluated by using IIEF-EF and EHS. Hemodynamic improvement was measured objectively via flow mediated dilatation (FMD) technique in some well-designed RCTs $(10,28)$, although these data were limited and not suitable for 
Table 1- Characteristics of the included studies in the systematic review.

\begin{tabular}{|c|c|c|c|c|c|c|c|}
\hline ID & Study & Country & Sensitivity to PDE5i & $\begin{array}{c}\text { No. of } \\
\text { patients }\end{array}$ & Intervention ${ }^{+}$ & End points & Outcomes \\
\hline $\begin{array}{l}\text { Vardi Y. } \\
2010 \text { (9) }\end{array}$ & $\begin{array}{l}\text { Single } \\
\text { arm }\end{array}$ & Israel & Responders & 20 & $\begin{array}{c}\text { 1; without } \\
\text { PDE5i }\end{array}$ & $\begin{array}{l}\text { A change in the IIEF-ED } \\
\text { domain score of }>5 \text { points was } \\
\text { used as the main measure of } \\
\text { treatment success. }\end{array}$ & $\begin{array}{l}\text { At } 1 \text { mo follow- } \\
\text { up, 1) } 20.9 \pm 5.8 \text { vs. } \\
13.5 \pm 4.1 \text { (baseline), } p< \\
0.001 \text { in IIEF-ED scores } \\
\text { remaining unchanged } \\
\text { at } 6 \text { mo; } 2 \text { ) Significant } \\
\text { increasing in the duration } \\
\text { of erection and penile } \\
\text { rigidity, and significant } \\
\text { improvement in penile } \\
\text { endothelial function; } 3 \text { ) Ten } \\
\text { men did not require any } \\
\text { PDE5-I therapy after 6-mo } \\
\text { follow-up. }\end{array}$ \\
\hline
\end{tabular}

\begin{tabular}{|c|c|c|c|c|c|}
\hline $\begin{array}{l}\text { Vardi Y. } \\
2012 \text { (10) }\end{array}$ & RCT & Israel & Responders & $\begin{array}{c}40 \\
\text { (treatment) } \\
\text { vs. } 20 \\
\text { (placebo) }\end{array}$ & $\begin{array}{c}\text { 1; without } \\
\text { PDE5i }\end{array}$ \\
\hline $\begin{array}{l}\text { Gruenwald } \\
\text { I. } 2012 \\
(11)\end{array}$ & $\begin{array}{c}\text { Single } \\
\text { arm }\end{array}$ & Israel & Non-responders & 29 & $\begin{array}{l}\text { 1; without } \\
\text { PDE5i at } \\
4 \text { w after } \\
\text { completing } \\
\text { LI-ESWT } \\
\text { (FU1) and } \\
\text { use it after } \\
8 \text { w (FU2). }\end{array}$ \\
\hline
\end{tabular}

Primary end point: A 5-point or greater improvement in the IIEF-EF between baseline and at $4 \mathrm{w}$ after treatment.

Secondary end point: Significant increase in the IIEF subcategories. An increase in EHS from $\leq 2$ at baseline to $\geq 3$ at $4 \mathrm{w}$ after treatment, and an improvement in penile blood flow.

Change in IIEF-ED, EHS and three parameters of penile hemodynamics and endothelial function.
1) Increase in IIEF-EF score: $6.7 \pm 0.9$ (LI-ESWT) vs. $3.0 \pm 1.4$ (sham), $\mathrm{p}=0.0322$; 2) 19 (LIESWT) vs. none (sham) in patients with baseline EHS $\leq 2$ having EHS $\geq 3$ after treatment; 3) 8.2 vs. $0.1 \mathrm{ml}$ $/ \mathrm{m} / \mathrm{dl}$ in FMD, $\mathrm{p}<0.0001$.

1) Mean IIEF-ED scores increased from $8.8 \pm 1$

(baseline) to $12.3 \pm 1$ at FU1 $(P=0.035)$. At FU2 (on active PDE5i treatment), their IIEF-ED further increased to $18.8 \pm 1(\mathrm{P}<$ 0.0001 ); 2) $72.4 \%$ (P< 0.0001 ) reached an EHS of $\geq 3$; 3) A significant improvement $(P=0.0001)$ in penile hemodynamics and this improvement significantly was correlating with increases in the IIEFED $(P<0.05)$.

Twenty-nine men $(57 \%$,

Primary end point: The treatment success threshold was set at EHS 3-4.

(treatment) ; without

vs. 54 (placebo ) without the use of
Secondary end point: An increase in IIEF-EF domain score of at least 5 points. active group) were able to have sexual intercourse medication vs. 5 men $(9 \%$, placebo group, $p=0.0001$ ) after 5 weeks of completing LI-ESWT. But no significant result was found with the use of the IIEF-EF. 


\begin{tabular}{|c|c|c|c|}
\hline $\begin{array}{l}\text { Yee C.H. } \\
2014 \text { (18) }\end{array}$ & RCT & China & Unknown \\
\hline $\begin{array}{l}\text { Bechara A. } \\
2015(19)\end{array}$ & $\begin{array}{c}\text { Single } \\
\text { arm }\end{array}$ & Argentina & Non-responders \\
\hline $\begin{array}{l}\text { Chung E. } \\
2015 \text { (20) }\end{array}$ & $\begin{array}{l}\text { Single } \\
\text { arm }\end{array}$ & Australia & $\begin{array}{c}\text { Failed or } \\
\text { unsatisfactory } \\
\text { outcome with } \\
\text { oral PDE5i and/or } \\
\text { vasoactive agents }\end{array}$ \\
\hline
\end{tabular}

25 treatment) vs. 28 (placebo)

3; use PDE5i

Whenever patients improved on all IIEF-6, SEP2 and SEP3 and to respond positively to the GAQ at 3 months posttreatment.

30

4; Whether other modality being used was unknown.

Change in IIEF-5 and EDITS scores, and overall satisfaction rate were recorded at 6 weeks and 4 months after completion of LI-ESWT.

\begin{tabular}{|c|c|c|c|c|c|}
\hline $\begin{array}{l}\text { Qi T. } 2015 \\
(21)\end{array}$ & $\mathrm{RCT}$ & China & Unknown & $\begin{array}{c}30 \text { (LI- } \\
\text { ESWT) vs. } \\
30 \text { (vacuum } \\
\text { erectile } \\
\text { device) }\end{array}$ & $7 ;$ unknown \\
\hline $\begin{array}{l}\text { Pelayo- } \\
\text { Nieto M. } \\
2015 \text { (22) }\end{array}$ & $\begin{array}{c}\text { Single } \\
\text { arm }\end{array}$ & Mexico & Unknown & 15 & $\begin{array}{c}\text { 3; unknown } \\
\text { medication } \\
\text { history }\end{array}$ \\
\hline
\end{tabular}

Reisman Single Netherlands, Responders and Y. 2015 (23)

$\begin{array}{ccc}\text { Single } & \text { Netherlands, } & \text { Responders and } \\ \text { arm } & \text { et al } & \text { Non-responders }\end{array}$

At 1 mo after LI-ESWT. 1) Cure: IIEF-5 score $\geq 22$ pts, or SEP, GAQ and EHS is 5, 2 and when IIEF-5 score<22pts, a 5-point or greater improvement in the IIEF-5, or $S E P \geq 4 \mathrm{pts}, \mathrm{GAQ} \geq 1 \mathrm{pts}$, EHS $\geq 3 p t s ; 3)$ Fail: IIEF-5 score $<21$ pts and improvement score $\leq 4 \mathrm{pts}, \mathrm{SEP}<3 \mathrm{pts}$, $\mathrm{GAQ}=0 \mathrm{pts}, \mathrm{EHS}<2 \mathrm{pts}$.

In IIEF-EF, success of treatment was defined as an increase of $>2$ points and $>5$ points in groups of mild and moderate, respectively. Results were evaluated by using IIEF, EHS, SEP, GAQ at 1 and 6 months after treatment. 2; without PDE5i until 1 month post treatments.

Primary end point: An increase of IIEF-EF score from baseline to the third follow-up (6m post treatment) $4 p t s$, respectively; 2) Relief:

At 4w follow-up, 1) mean IIEF-ED score: $17.8 \pm 4.8$ (LI-ESWT) vs. $15.8 \pm 6.1$ (sham), $p=0.156 ; 2$ ) mean EHS: $2.7 \pm 0.5$ (LI-ESWT) and $2.4 \pm 0.9$ (sham), $p=$ 0.163 .

$60 \%(12 / 20)$ of the patients responded to the treatment.

At 6 weeks and $4 \mathrm{~m}, 60 \%$ of patients reported an improvement in IIEF-5 score by 5 points, $70 \%$ improvement in EDITS Index score by $>50 \%$. $67 \%$ of patients satisfied (scoring 4 out of 5) and $80 \%$ would recommend the therapy.

The number of cured patient was 14 and the number of relief was 8 . Effective rate was $73 \%$ (22/30) in LI-ESWT group.

The rate of success was 80\%. 1) IIEF: 15 (11-18) pts at baseline vs. 20 (11-

23) pts at 1 and $6 \mathrm{mo}$, $\mathrm{p}<0.013$; 2) EHS: $2(2-3)$ pts at baseline vs. $4(2-4)$

pts at $1 \mathrm{mo}, \mathrm{p}<0.01 ; 3$ ) SEP3: 7 patients at baseline vs. 12 patients at $1 \mathrm{mo}$, $p=0.0013$. according to the initial ED severity: >2-point increase for mild symptoms; $>5$ points for moderate symptoms; and $>7$ points for severe symptoms.
$47(81 \%)$ had a successful treatment. 


\begin{tabular}{|c|c|c|c|c|c|c|}
\hline $\begin{array}{l}\text { Ruffo } \\
\text { A. } 2015 \\
\text { (24) }\end{array}$ & $\begin{array}{c}\text { Single } \\
\text { arm }\end{array}$ & Italy & Non-responders & 31 & $\begin{array}{l}\text { 2; without } \\
\text { PDE5i } \\
\text { during } \\
\text { treatment. }\end{array}$ & $\begin{array}{l}\text { Primary end point: An } \\
\text { increase of IIEF-EF score } \\
\text { from baseline to } 1 \text { and } 3 \\
\text { months after LI-ESWT. } \\
\text { Secondary end point: } \\
\text { Improvement in SEP2, } 3 \text { and } \\
\text { GAQ. }\end{array}$ \\
\hline
\end{tabular}

\begin{tabular}{|c|c|c|c|c|}
\hline $\begin{array}{l}\text { Srini V.S. } \\
2015 \\
(25)\end{array}$ & RCT & India & Responders & $\begin{array}{c}60 \\
\text { (treatment) } \\
\text { vs. } 17 \\
\text { (placebo ) }\end{array}$ \\
\hline
\end{tabular}

$\begin{array}{lcc}\text { Hisasue } & \text { Single } & \text { Japan } \\ \text { S. } 2016 & \text { arm } & \\ (26) & \end{array}$

\begin{tabular}{|c|c|c|c|}
\hline $\begin{array}{l}\text { Frey A. } \\
2016 \\
(27)\end{array}$ & $\begin{array}{l}\text { Single } \\
\text { arm }\end{array}$ & Denmark & $\begin{array}{l}\text { Postprostatectomy } \\
\text { ED with unknown } \\
\text { sensitivity to PDE5i }\end{array}$ \\
\hline
\end{tabular}

\begin{tabular}{|c|c|c|c|c|c|}
\hline $\begin{array}{l}\text { Kitrey } \\
\text { N.D. } \\
2016 \\
(28)\end{array}$ & RCT & Israel & Non-responders & $\begin{array}{c}37 \\
\text { (treatment) } \\
\text { vs. } 18 \\
\text { (placebo ) }\end{array}$ & $\begin{array}{l}\text { 1; use } \\
\text { PDE5i when } \\
\text { evaluating } \\
\text { results. }\end{array}$ \\
\hline
\end{tabular}

Primary end point: $\geq 5$ points improvement in the IIEF-EF between baseline and $1 \mathrm{mo}$ (also $12 \mathrm{mo}$ ).

Secondary end point: Significant increase in the CGIC and an increase in EHS from $\leq 2$ at baseline to $\geq 3$ at FU1 and FU5.

Unknown

56

1; use

PDE5i on-demand after LI-

ESWT.

16

6 ; use of erectogenic aids

Primary end point: Changes in IIEF-5 scores. Secondary end point: A global satisfaction question ranging from "very dissatisfied" to "very satisfied".

Main outcomes: 1) EHS was 3 or greater; 2) A change in IIEF-EF was greater than

7 points for severe ED and 5 points for moderate ED. Secondary outcome: FMD penile time-flow AUC as an indicator of penile endothelial function and the CGIC questionnaire. They were evaluated at 1 month after the end of treatment.
1) IIEF-EF: $16.54 \pm 6.35$ (baseline) vs. $21.13 \pm 6.31$

(1 mo), $21.03 \pm 6.38$ (3 mo). 2) SEP2 (yes): $61 \%$ (baseline) vs. $86 \%$ (1mo), $89 \%$ (3 mo). 3) SEP3 (yes): $32 \%$ (baseline) vs. $58 \%$ (1mo), 62\% (3 mo); all $p<0.05$. 4) GAQ: at 1 and $3 \mathrm{mo}$, difference is not significant.

1) Increase in IIEF-EF: at $1 \mathrm{mo}, 12.5 \mathrm{pts}$ in LIESWT group vs. 1.4 pts in control group; at $12 \mathrm{mo}$, 8.7 pts in LI-ESWT group vs. NA in control group. 2) Effective rate in EHS: $90 \%(1 \mathrm{~m}), 83 \%(12 \mathrm{~m})$ vs. none (placebo group) 3) Data about CGIC were not provided.

$64.2 \%$ patients showed improvement in SHIM scores, and $57.1 \%$

patients achieved an EHS 3 or 4 without PDE5i within 6 months after

LI-SWT. MPCC showed significant improvement in $64 \%$ patients from 1 month after treatment, maintaining it until 6 months.

The median change in IIEF- 5 scores was +3.5 (range -1 to $8 ; p=0.0049$ ) and +1 (range -3 to $14 ; p=0.046) ; 11$ and 7 patients reported being either satisfied or very satisfied at 1 mo follow up and 1 year follow up, respectively.

1) $54.1 \%$ (LIST) vs. none (sham) had EHS=3, $p<0.0001 ; 2)$ in IIEF-EF, $40.5 \%$ (LIST) vs. none (sham), $p=0.001 ; 3$ ) $56.3 \%$ of the patients treated with active LIST after sham treatment achieved an erection hard enough for penetration $(p<0.005) ; 4)$ The change in penile hemodynamic parameters was

statistically significant; 5 ) According to CGIC, 56.8\% of patients (LIST) vs.

$27.8 \%$ (sham) $(\mathrm{p}=0.051)$ reported clinical improvement. 
Table 2-The reported protocols of LI-ESWT in included studies.

\begin{tabular}{|c|c|c|c|c|c|}
\hline ID & Device & Energy density & Frequency & Distribution of energy & Cycle of treatment \\
\hline 1 & $\begin{array}{l}\text { Omnispec } \\
\text { ED1000 } \\
\text { (Medispec } \\
\text { Ltd., Yehud, } \\
\text { Israel / } \\
\text { Germantown, } \\
\text { MD, USA) }\end{array}$ & $\begin{array}{c}1500 \text { shocks of } \\
0.09 \mathrm{~mJ} / \mathrm{mm}^{2}\end{array}$ & 120 shocks /min & $\begin{array}{l}300 \text { shocks were } \\
\text { delivered at each of the } \\
5 \text { treatment points (the } \\
\text { distal, mid and proximal } \\
\text { penile shaft, and to the } \\
\text { left and right crura). }\end{array}$ & $\begin{array}{l}\text { Nine-week treatment period: two LI- } \\
\text { ESWT sessions per week for } 3 \text { weeks, } \\
\text { repeated after a 3-week no treatment } \\
\text { interval / twice a week for } 4 \text { weeks }\end{array}$ \\
\hline 2 & $\begin{array}{l}\text { Renova }{ }^{\circledR}( \\
\text { Direx Group } \\
\text { LTD) }\end{array}$ & $\begin{array}{c}3600 \text { shocks of } \\
0.09 \mathrm{~mJ} / \mathrm{mm}^{2}\end{array}$ & $\begin{array}{c}\text { a maximum rate } \\
\text { of } 300 \text { shocks/ } \\
\text { min }\end{array}$ & $\begin{array}{c}900 \text { shocks were } \\
\text { delivered at each of } \\
\text { the } 4 \text { treatment points } \\
\text { (left and right corpus } \\
\text { cavernosum, left and } \\
\text { right crus). }\end{array}$ & One session per week for 4 weeks. \\
\hline 3 & Renova $®$ & $\begin{array}{c}5000 \text { shocks of } \\
0.09 \mathrm{~mJ} / \mathrm{mm}^{2}\end{array}$ & 300 shocks/min & $\begin{array}{l}900 \text { shocks at left and } \\
\text { right corpus cavernosum; } \\
1600 \text { shocks at left and } \\
\text { right crus. }\end{array}$ & One session per week for 4 weeks. \\
\hline 4 & $\begin{array}{l}\text { Duolith }{ } \text { SD1 } \\
\text { ultra (Storz } \\
\text { Medical AG, } \\
\text { Tägerwilen, } \\
\text { Switzerland) }\end{array}$ & $\begin{array}{c}3000 \text { shocks of } \\
0.25 \mathrm{~mJ} / \mathrm{mm}^{2}\end{array}$ & $6 \mathrm{~Hz}$ & $\begin{array}{l}\text { Distal penis }(1000 \\
\text { shocks), base of penis } \\
(1000 \text { shocks), and } \\
\text { corporal bodies on } \\
\text { perineum( } 500 \text { shocks to } \\
\text { each crura) }\end{array}$ & Twice weekly for 6 weeks \\
\hline 5 & $\begin{array}{l}\text { Duolith }{ }^{\circledR} \text { SD1 } \\
\text { ultra (Storz } \\
\text { Medical AG, } \\
\text { Tägerwilen, } \\
\text { Switzerland) }\end{array}$ & $\begin{array}{c}3000 \text { shocks of } \\
0.15 \mathrm{~mJ} / \mathrm{mm}^{2}\end{array}$ & $5 \mathrm{~Hz}$ & $\begin{array}{l}\text { Six treatment sites } \\
\text { ( distal, central and } \\
\text { proximal part of each } \\
\text { corpus cavernosum ) }\end{array}$ & One session per week for 5 weeks. \\
\hline 6 & $\begin{array}{l}\text { Duolith }{ }^{\circledR} \text { SD1 } \\
\text { T-Top (Storz } \\
\text { Medical, } \\
\text { Tägerwilen, } \\
\text { Switzerland) }\end{array}$ & $\begin{array}{c}1000 \text { shocks } \\
\text { of } 20 \mathrm{~mJ} / \\
\mathrm{mm}^{2}, 15 \mathrm{~mJ} / \\
\mathrm{mm}^{2} \text { and } 12 \mathrm{~mJ} / \\
\mathrm{mm}^{2}\end{array}$ & $5 \mathrm{~Hz}$ & $\begin{array}{l}\text { Shocks of } 20 \mathrm{~mJ} / \mathrm{mm}^{2} \text {, } \\
15 \mathrm{~mJ} / \mathrm{mm}^{2}, 12 \mathrm{~mJ} / \mathrm{mm}^{2} \\
\text { were applied to the root } \\
\text { of penis, to the shaft, } \\
\text { and at a few millimeters } \\
\text { proximal to the glans, } \\
\text { respectively. }\end{array}$ & $\begin{array}{c}\text { Twice sessions every other week for six } \\
\text { weeks }\end{array}$ \\
\hline 7 & $\begin{array}{l}\text { LGT- } \\
\text { 2500B(Long } \\
\text { Zhi-jie Ltd, } \\
\text { Guangzhou, } \\
\text { China) }\end{array}$ & $\begin{array}{c}1500 \text { shocks of } \\
1 \text { bar }\end{array}$ & $2 \mathrm{~Hz}$ & $\begin{array}{l}300 \text { shocks were } \\
\text { delivered at each of the } \\
5 \text { treatment points (the } \\
\text { distal, mid and proximal } \\
\text { penile shaft, and the left } \\
\text { and right crura). }\end{array}$ & Twice a week for 4 weeks \\
\hline
\end{tabular}


Figure 2 - Forest plots of random effects model of risk ratio of effective treatment of LI-ESWT for ED in terms of International Index of Erectile Function-Erectile Function Domain (a) and Erectile Hardness Score (b).

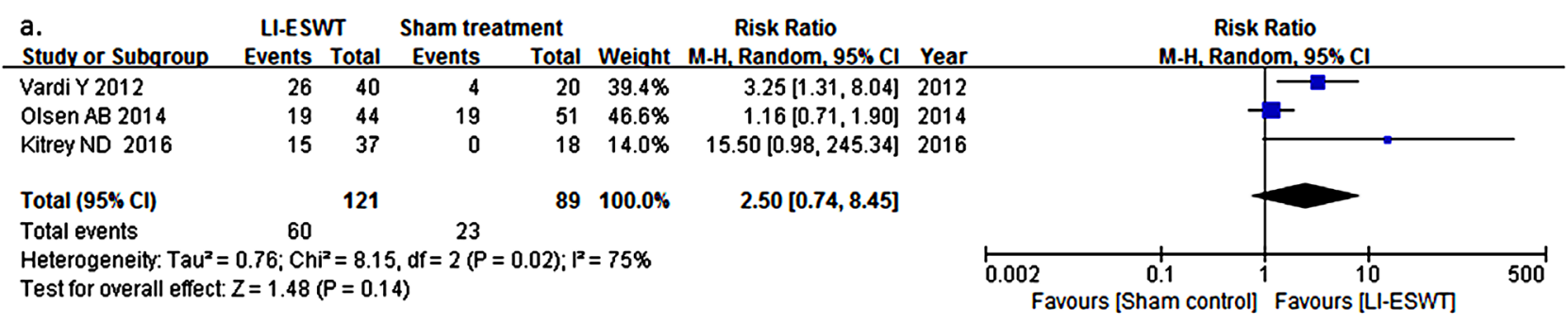

\begin{tabular}{|c|c|c|c|c|c|c|c|}
\hline \multirow{2}{*}{$\begin{array}{l}\text { b. } \\
\text { Study or Subqroup }\end{array}$} & \multirow{2}{*}{\multicolumn{2}{|c|}{$\begin{array}{l}\text { LI-ESWT } \\
\text { Events Total }\end{array}$}} & \multicolumn{2}{|c|}{ Sham treatment } & \multicolumn{3}{|c|}{ Risk Ratio } \\
\hline & & & Events & Total & Weight & M.H, Random, $95 \% \mathrm{Cl}$ & Year \\
\hline Vardi Y 2012 & 19 & 28 & 0 & 12 & $7.8 \%$ & $17.48[1.14,268.01]$ & 2012 \\
\hline Olsen AB 2014 & 29 & 51 & 5 & 54 & $76.8 \%$ & $6.14[2.58,14.64]$ & 2014 \\
\hline Srini vS 2015 & 54 & 60 & 0 & 17 & $7.7 \%$ & $32.16[2.09,495.35]$ & 2015 \\
\hline Kitrey ND 2016 & 20 & 37 & 0 & 18 & $7.7 \%$ & $20.50[1.31,320.94]$ & 2016 \\
\hline Total $(95 \% \mathrm{Cl})$ & & 176 & & 101 & $100.0 \%$ & $8.31[3.88,17.78]$ & \\
\hline Total events & 122 & & 5 & & & & \\
\hline $\begin{array}{l}\text { Heterogeneity: Ta } \\
\text { Test for overall eff }\end{array}$ & $\begin{array}{l}0 ; \mathrm{Ch} \\
5.45\end{array}$ & & & & & & \\
\hline
\end{tabular}

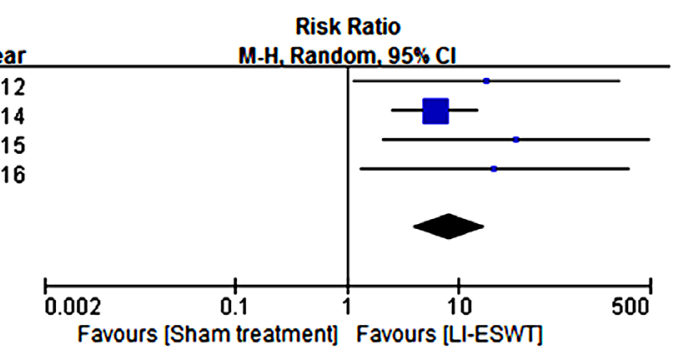

cumulative analysis. In preclinical researches, it was revealed that LI-ESWT could induce angiogenesis, nerve regeneration, progenitor cell recruitment, endothelial functional improvement, tissue remodeling reverse, and microenviroment improvement to improve EF $(29,30)$. In addition, there was no adverse side effect reported. Overall, current evidences support LI-ESWT as a potential choice for ED clinically and preclinically.

Recently, two systematic reviews and metaanalyses $(12,13)$ on the topic were published and their conclusions were similar to ours. However, there were some limitations in their study designs. The study by Lu et al. (12) included seven RCTs on LI-ESWT for organic ED and ED associated with PD and CPP. Heterogeneity was evident pathologically and clinically among the three types of ED (31). Furthermore, a recent meta-analysis proved that PD-associated ED could not benefit from extracorporeal shockwave therapy (32). Therefore, the application possibility of cumulative results was reduced and subgroup analysis was not convincing enough when explaining the exact source of heterogeneity based on their inclusion criteria. It is more reasonable to separate different
ED according to pathogenesis when the efficacy of LI-ESWT was evaluated. The other study by Angulo et al. (13) included single arm trials with evidence level 2, inevitably lowering the quality of their meta-analysis. Our meta-analysis focused on RCTs regarding organic ED with similar inclusion/ exclusion criteria and excluded studies on CPPand PD-associated disease. In our opinion, our design is the most reasonable among the three meta-analyses.

Different protocols of LI-ESWT likely influence its therapeutic effect on ED, and more frequent treatment and longer treatment course seems to be more effective, although there is no comparative trial to define the best protocol. Our analysis revealed that 9-week protocol with 12 sessions, which was proposed by Vardi et al. (9) and used most frequently, was more effective than 5-week protocol with 5 sessions. In a study evaluating additional shock wave therapy, it was demonstrated that "second round" LI-ESWT was essential for patients with poor response to the previous treatment (33). Nevertheless, shorter LIESWT protocols were also investigated because repeated visits to hospital and long duration of treatment could compromise patient's compliance 
Figure 3 - Relationship of clinical variables and treatment procedures in International Index of Erectile Function-Erectile Function Domain (IIEF-EF). (a) The studies using the 9-week protocol of LI-ESWT more possibly contributed to effective

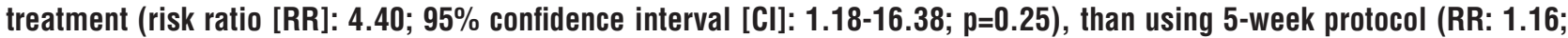
95\% Cl: 0.71-1.90), although it did not reach statistical significance $(\mathrm{p}=0.06)$. (b) LI-ESWT for PDE5I non-responders more possibly contributed to effective treatment (RR: 15.50 ; 95\% Cl: 0.98-245.34), than for responders (RR: $1.81 ; 95 \%$ Cl: $0.64-$ $5.11 ; p=0.04)$, but it did not reach statistical significance neither $(p=0.15)$.

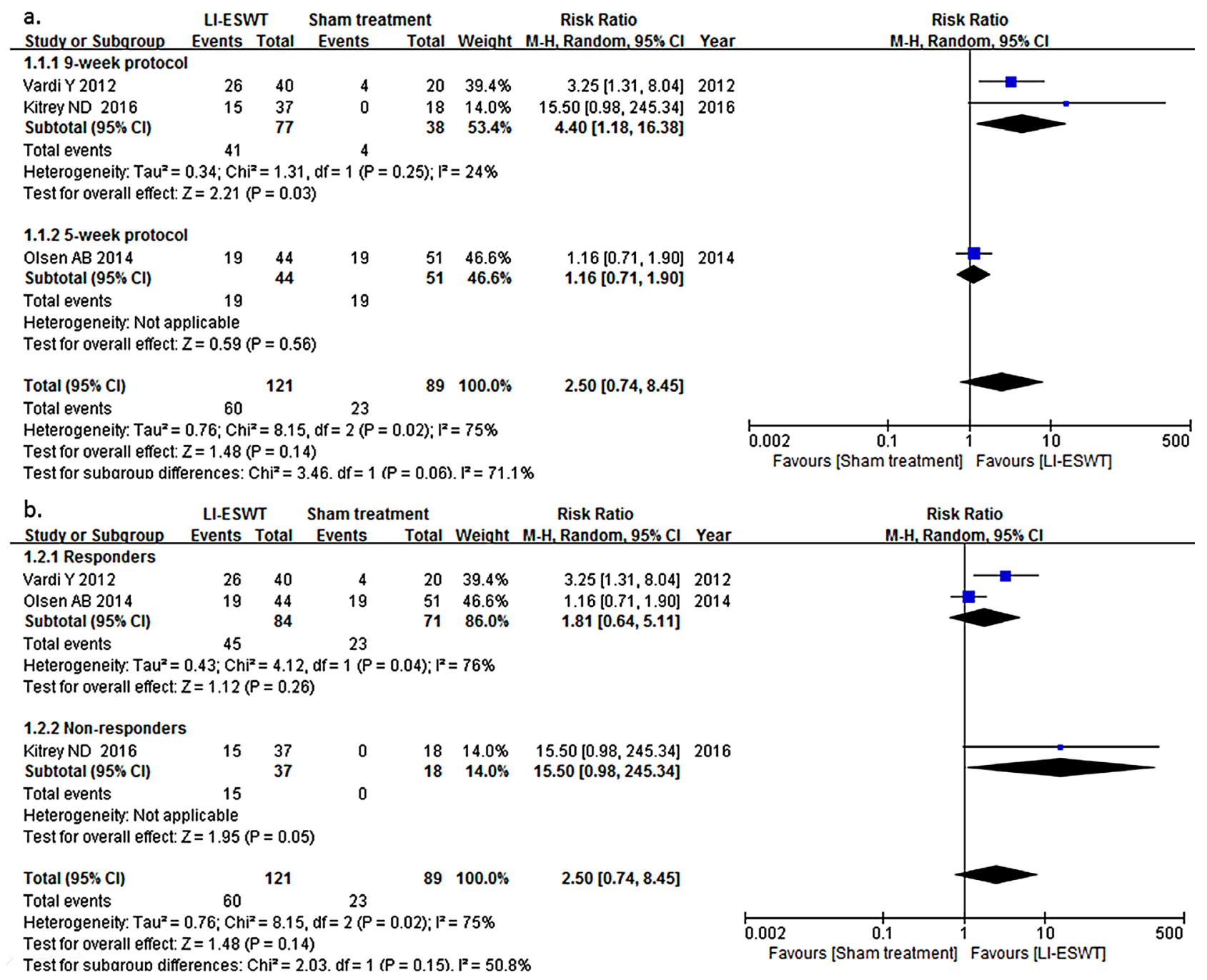

$(18,25)$, and favorable results of short protocols were also proven (22-24). Therefore, additional comparative studies among different protocols are demanded to create an optimal protocol.

Energy density (2) and dose (30) of shock wave therapy are considered to be relative to physiological effect. As regard to penile tissue, high energy level causes apoptosis and collagenization of corporal smooth muscle with consequently deteriorating EF (34). When low energy shock wave therapy was conducted in the treatment of diabetic ED, EF was significantly improved with increased smooth muscle and endothelial content. Meanwhile, it was proven that improvement was more significant in the 300-shock group than in the 100- and 200-shock groups (30). The cumulative analysis revealed that 9-week protocol with energy density of $0.09 \mathrm{~mJ} / \mathrm{mm}^{2}$ and 1500 pulses 
Figure 4 - Relationship of clinical variables and treatment procedures in the Erection Hardness Score (EHS). (a) The studies using the 9-week protocol of LI-ESWT more possibly contributed to effective treatment (risk ratio [RR]: 22.59; 95\% confidence interval [CI]: 4.65-109.79; $\mathrm{p}=0.95)$, than using 5-week protocol (RR: 6.14; 95\% CI: 2.58-14.64), although it did not reach statistical significance $(\mathrm{p}=0.16)$. (b) LI-ESWT for PDE5I non-responders more possibly contributed to effective treatment (RR: 20.50; 95\% Cl:1.31-320.94), than for responders (RR: 8.58; 95\% Cl: 3.17-23.23; $p=0.32$ ), but it did not reach statistical significance $(p=0.56)$. (c) The outcome of studies with consistent risk factor of ED between treatment and control group is Iower (RR: 7.41; 95\% Cl: 3.36-16.38; $\mathrm{p}=0.52$ ), than that with inconsistent risk factors (RR: 32.16; 95\% Cl: 2.09-495.35), but it did not reach statistical significance $(p=0.31)$.

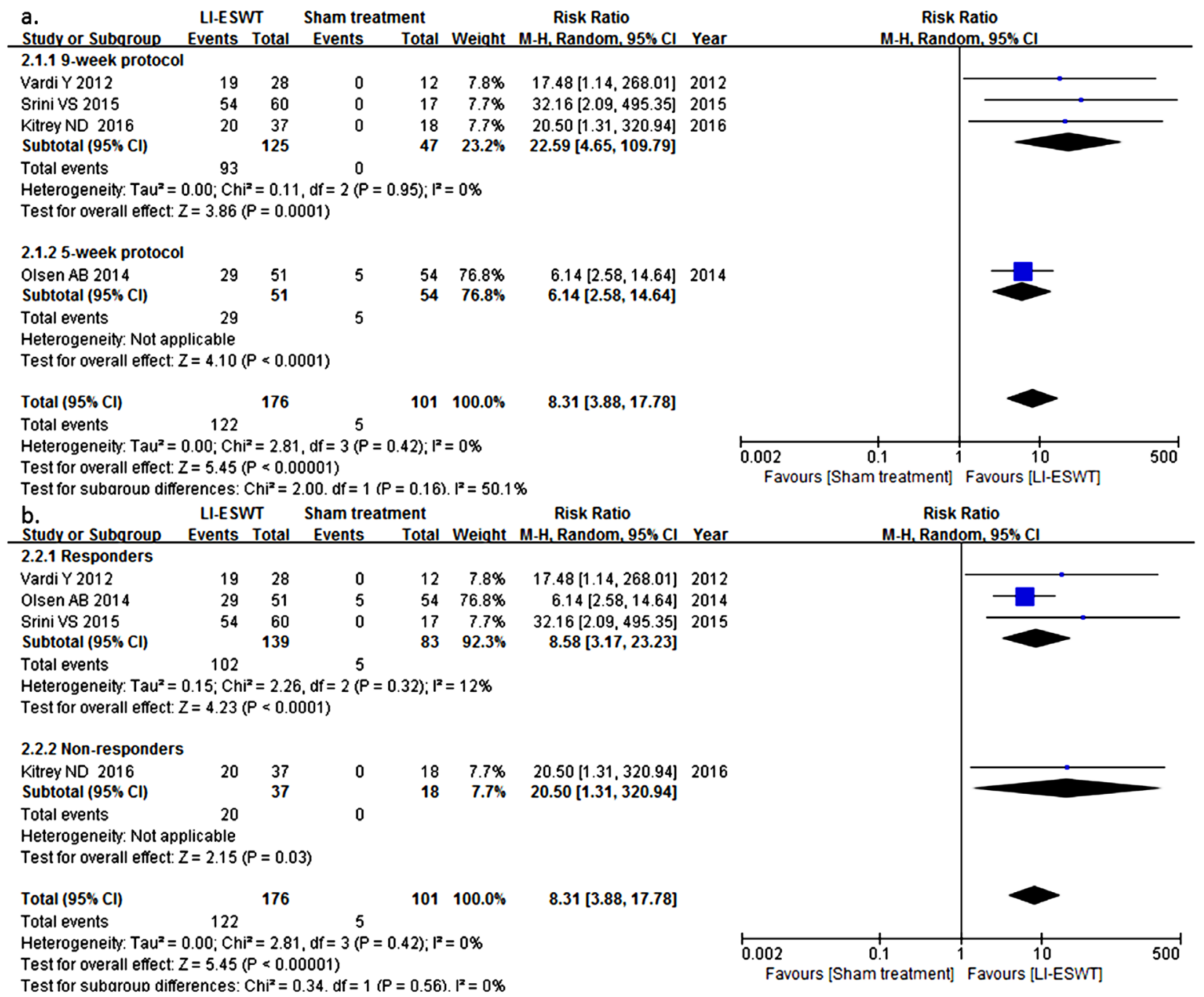

(300 for each treatment site) seemed to be superior to 5 -week protocol with energy density of $0.15 \mathrm{~mJ} /$ $\mathrm{mm}^{2}$ and 3000 pulses (500 for each site). However, an optimal energy density and number of pulses could not be further defined separately because of limited literature. In fact, no agreement exists on optimal energy and dose range for LI-ESWT and current literature reveal that energy density and dose applied in the field of ED with promising effect usually range from $0.09 \mathrm{~mJ} / \mathrm{mm}^{2}$ to $0.25 \mathrm{~mJ} /$ $\mathrm{mm}^{2}$ and 1500 to 5000 times (300-1600 shocks for each site) respectively. Direct comparative trials and more precise preclinical researches are essential to make optimal parameters.

Compared to second- and third-line therapy for ED, intracavernosal injection of 


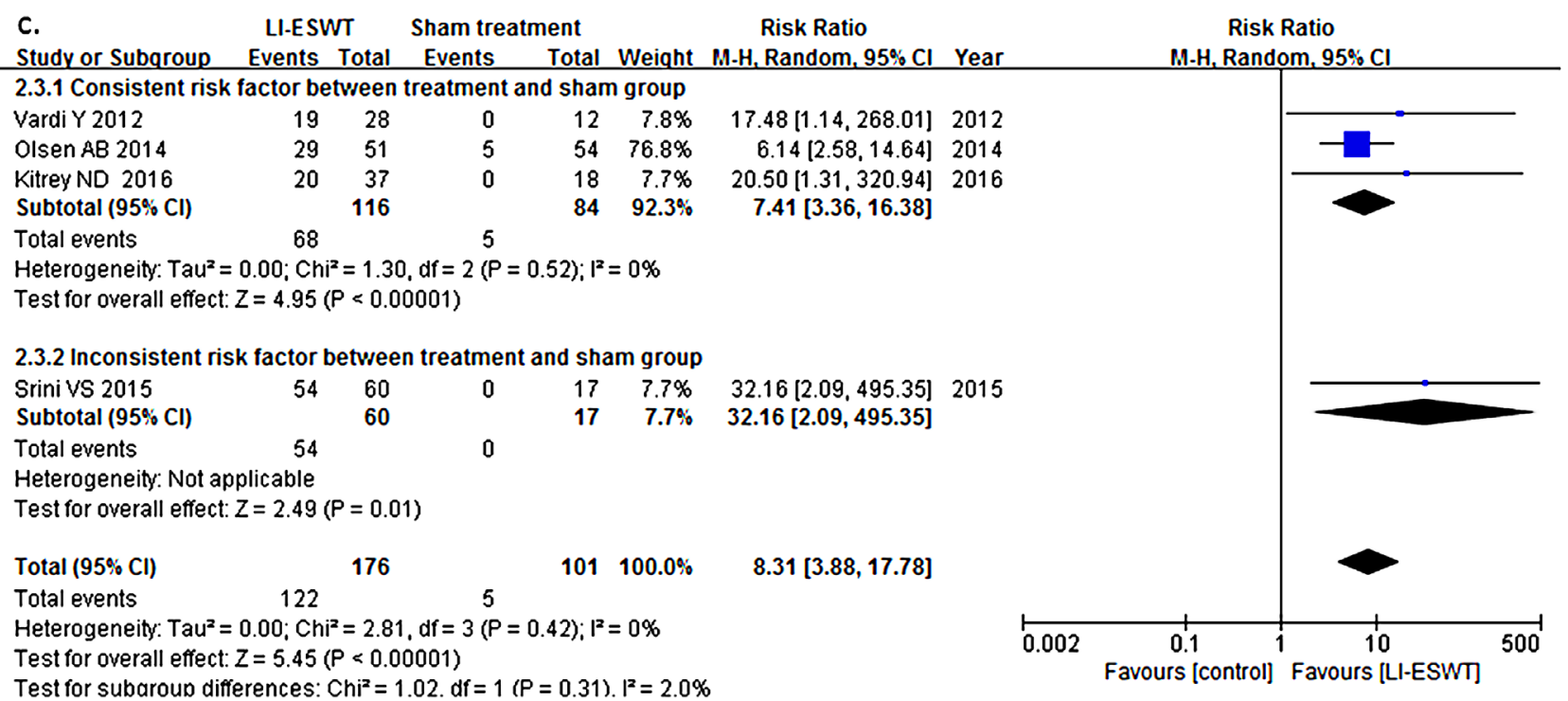

Table 3 - Baseline characteristics of study population in 4 RCTs for meta-analysis.

\begin{tabular}{|c|c|c|c|c|c|c|c|c|c|}
\hline Study & $\begin{array}{c}\text { Age[median(years), } \\
\text { range] }\end{array}$ & EHS & IIEF & Diabetes & Hypertension & Heart disease & Smoking & Alcohol & Lipids \\
\hline $\begin{array}{l}\text { Vardi } \\
2012(10)\end{array}$ & $\begin{array}{c}58 \text { (27-72) vs. } 57 \\
(35-77) \#\end{array}$ & $\leq 2$ & IIEF-EF < 19 & 30 vs. $30 \% \#$ & ND & 20 vs. $10 \% \#$ & ND & NA & ND \\
\hline $\begin{array}{l}\text { Olsen } 2014 \\
(17)\end{array}$ & $\begin{array}{c}59(41-80) \text { vs. } \\
60(37-79)\end{array}$ & $<2$ & IIEF-EF < 20 & 18 vs. $13 \% \#$ & 33 vs. $37 \% \#$ & 4 vs. $11 \% \#$ & ND & ND & NA \\
\hline $\begin{array}{l}\text { Srini } \\
2015(25)\end{array}$ & NA & $\leq 2$ & IIEF-EF < 18 & ND & $\begin{array}{c}22.11 \text { vs. } 5 \% \\
(p=0.0219)\end{array}$ & $\begin{array}{c}3.16 \text { vs. } 25 \% \\
(p=0.0003)\end{array}$ & ND & $\begin{array}{l}23.16 \text { vs. } 47.5 \% \\
\quad(p=0.0074)\end{array}$ & $\begin{array}{c}20 \text { vs. } 47.5 \% \\
(p=0.0017)\end{array}$ \\
\hline $\begin{array}{l}\text { Kitrey } 2016 \\
(28)\end{array}$ & $\begin{array}{c}60 \text { (28-78) vs. } 64 \\
(29-81) \#\end{array}$ & $\leq 2$ & $\mathrm{IIEF-EF} \leq 12$ & $\begin{array}{l}56.8 \text { vs. } \\
72.2 \% \#\end{array}$ & ND & $\begin{array}{l}48.6 \text { vs. } \\
38.9 \% \#\end{array}$ & ND & NA & ND \\
\hline
\end{tabular}

The former is a LI-ESWT group and the latter is a controlled group in the blank. \#: No significant differences between groups. ND: no significant differences. NA: not applicable.

vasoactive drugs and surgical implantation of penile prostheses, LI-ESWT is noninvasive and rehabilitative. Severe ED patients who didn't respond to the first-line therapy of PDE5is could benefit from the treatment $(11,19,20,28)$. Our analysis revealed that non-responders, moderate to severe EDs with baseline IIEF-EF $\leq 12$, appeared to have more possibility to benefit from LIESWT than responders with baseline IIEF-EF $<20$. Interestingly, the only RCT (18) with low risk of bias suggested that although improvement in IIEFEF in the LI-ESWT group didn't reach significant difference compared to the sham group as a whole, the former's elevated IIEF-EF score was significantly higher than the latter's in subgroup analysis of severe ED patients with Sexual Health Inventory for Men (SHIM) score 5-7. Nevertheless, underlying association between the severity of ED and therapeutic impact of LI-ESWT is not clear and requires further investigation.

In addition to baseline EF, other patient characteristics, such as age, DM, hypertension, heart disease, smoking and/or alcohol consumption, and lipid level, potentially influence the effect of LI-ESWT on ED and thus different proportion of age and comorbidities between the treatment and control group, among different RCTs, likely commits the result of a RCT and meta-analysis. Almost 
all included RCTs provided participant's information regarding age and comorbidities, but there was no further investigation to determine the impact of age and comorbidities on the effect of LI-ESWT. In the study by Srini et al. (25), comorbidities were inconsistent between the treatment and control group with higher incidence in the latter. Although RR appeared to be far higher in the Srini's study than the other three studies $(10,17,28)$ having consistent comorbidities between the treatment and control group, our analysis still cannot answer the question on whether comorbidities are associated with the effectiveness of LI-ESWT because the difference did not reach statistical significance. Therefore, RCTs with stratification of age and comorbidities are needed to determine the impact of these factors on the effect of LI-ESWT for patients with ED.

Short-term effective treatment defined as "participant's score increased by at least 5 points more than baseline in IIEF-EF, or a patient (baseline EHS $\leq 2$ pts) with EHS $\geq 3$ pts at about 1 month after LI-ESWT" was accepted because most participants and RCTs could be included for meta-analysis. Data about the change of IIEF-EF after treatment in the manner of mean and standard deviation, which were used in the other two meta-analyses, were available in only one (18) of the five RCTs (35). The minimal clinically important difference (MCID) of IIEF-EF is considered to be ideal to assess the true clinical efficacy of an intervention (36) and has been gradually used in the clinical trials about LI-ESWT for $\operatorname{ED}(23,28)$. With more RCTs being published, meta-analysis on the topic using MCID as evaluation criteria is essential in the future.

The initial and optimal functional time of LI-ESWT is still unclear. The effect of LI-ESWT appears to be time-dependent in clinical practice. In the studies using 9-week protocol, the majority of patients felt improvement in EF initially between the sixth and eighth session $(10,11)$. The efficacy reached peak at 4-6 weeks after all sessions, then declined $(17,20$, $25)$. For about half of the patients, the positive effect would gradually wane over two ye- ars, most of whom were severe and diabetic ED patients (37). With aid of PDE5i, however, the peak effect could be showed at 6 months (23, 26). In the laboratory, it was identified previously that shockwave-induced neovascularization was evident at 4 weeks after the treatment and persisted for 12 weeks with angiogenesis-related factors beginning to rise in 1 week, keeping high for 8 weeks, and then decline at 12 weeks $(3,38)$. Based on aforementioned clinical and preclinical results, it is rational to evaluate the short-term effect on ED at about one month after LI-ESWT in the review.

There are few evidences on LI-ESWT for ED other than vasculogenic type. Nerve sparing prostatectomy ED could benefit from the method (27), while patients suffering from non-sparing nerve surgery probably not $(20,39)$. Nonetheless, it was revealed that LI-ESWT alone or combined with human adipose-derived stem cells (h-ADSCs) seemed to have ability to promote erectile function recovery in a rat model of ED with bilateral pelvic nerve injury $(40,41)$.

There are some limitations in this study. First, detailed individual patient data were not available from all the studies. In the review, not all included studies were used for meta-analysis due to heterogeneous endpoints. Nevertheless, the non-quantitative analyzed studies were listed as describable summary to support the use of LI-ESWT. Second, there was substantial variability among the studies, e.g., the severity of ED, age, comorbidity, device, energy density and distribution, frequency of treatment, interval between sessions, and aid of medication. These are confounding factors which likely influence efficacy and should be considered when defining optimal modality strategy. Third, although the confidence interval of RR exceeds the nullity line when efficacy was evaluated by IIEF-EF, the effective treatments were far more in the LI-ESWT group than in the controlled group in the Vardi's (10) and Kitrey's studies (28). After excluding the study by Olsen et al. (17) with obviously influencing stability of cumulative result, RR was 4.40 (95\%CI: 1.1816.38). The authors (17) explained that inconsistent results between using IIEF-EF and EHS 
were caused by a part of patients having some problems of understanding the questionnaires of IIEF-EF. Fourth, the quality and number of the eligible studies were relatively limited and none of the 4 RCT was elevated as low risk of bias. Meta-analysis on the basis of these RCTs likely influenced its reliability as level $1 \mathrm{a}$ evidence. Fifth, publication bias existed because of four factors: 1) only English and Chinese literatures were included; 2) other language, unpublished studies and conference abstracts were excluded; 3) inflated estimates by a flawed methodological design in smaller studies; 4) and/ or a lack of publication of small trials with opposite outcomes. Sixth, objective measured results, and middle- and long-term effects were unavailable in our meta-analysis due to lack of sufficient data.

\section{CONCLUSIONS}

In summary, LI-ESWT, as a noninvasive treatment, with potential short-term therapeutic effect on patients with organic ED irrespective of sensitivity to PDE5is. Owing to the limited number and quality of the studies, more large-scale, well-designed and long-term follow-up time studies are needed to confirm our analysis.

\section{ACKNOWLEDGEMENTS}

We thank Ms Zheng-yin Luo for the revision of manuscript. Ms Zheng-yin Luo with a major in English is from Law School, Guizhou Normal University, Guiyang, Guizhou, China. This work was supported by the Science and Technology Foundation of the Sichuan Province (2014JY0183 to Yi-ping Lu) and the Science and Technology Foundation of the Chengdu City (2014-HM01-00301-SF to Yi-ping Lu).

Zi-jun Zou and Liang-you Tang contributed equally to this work

\section{CONFLICT OF INTEREST}

None declared.

\section{REFERENCES}

1. Wespes E, Eardley I, Giuliano F, et al. Guidelines on male sexual dysfunction: Erectile dysfunction and premature ejaculation. The Netherlands: European Association of Urology; 2013. available at. <http://uroweb.org/wpcontent/uploads/14_Male-Sexual-Dysfunction_LR.pdf>

2. Abu-Ghanem Y, Kitrey ND, Gruenwald I, Appel B, Vardi Y. Penile low-intensity shock wave therapy: a promising novel modality for erectile dysfunction. Korean J Urol. 2014;55:295-9.

3. Wang CJ, Wang FS, Yang KD, Weng LH, Hsu CC, Huang $\mathrm{CS}$, et al. Shock wave therapy induces neovascularization at the tendon-bone junction. A study in rabbits. J Orthop Res. 2003;21:984-9.

4. Aicher A, Heeschen C, Sasaki K, Urbich C, Zeiher AM, Dimmeler $S$. Low-energy shock wave for enhancing recruitment of endothelial progenitor cells: a new modality to increase efficacy of cell therapy in chronic hind limb ischemia. Circulation. 2006;114:2823-30.

5. Ciccone MM, Notarnicola A, Scicchitano P, Sassara M, Carbonara S, Maiorano M, et al. Shockwave therapy in patients with peripheral artery disease. Adv Ther. 2012;29:698-707. Erratum in: Adv Ther. 2012;29:923.

6. Omar MT, Alghadir A, Al-Wahhabi KK, Al-Askar AB. Efficacy of shock wave therapy on chronic diabetic foot ulcer: a single-blinded randomized controlled clinical trial. Diabetes Res Clin Pract. 2014;106:548-54

7. Zuozienė G, Laucevičius A, Leibowitz D. Extracorporeal shockwave myocardial revascularization improves clinical symptoms and left ventricular function in patients with refractory angina. Coron Artery Dis. 2012;23:62-7.

8. Wang CJ, Yang YJ, Huang CC. The effects of shockwave on systemic concentrations of nitric oxide level, angiogenesis and osteogenesis factors in hip necrosis. Rheumatol Int. 2011;31:871-7.

9. Vardi Y, Appel B, Jacob G, Massarwi 0, Gruenwald I. Can low-intensity extracorporeal shockwave therapy improve erectile function? A 6-month follow-up pilot study in patients with organic erectile dysfunction. Eur Urol. 2010;58:243-8.

10. Vardi Y, Appel B, Kilchevsky A, Gruenwald I. Does low intensity extracorporeal shock wave therapy have a physiological effect on erectile function? Short-term results of a randomized, double-blind, sham controlled study. J Urol. 2012;187:1769-75.

11. Gruenwald I, Appel B, Vardi Y. Low-intensity extracorporeal shock wave therapy--a novel effective treatment for erectile dysfunction in severe ED patients who respond poorly to PDE5 inhibitor therapy. J Sex Med. 2012;9:259-64. 
12. Lu Z, Lin G, Reed-Maldonado A, Wang C, Lee YC, Lue TF. Low-intensity Extracorporeal Shock Wave Treatment Improves Erectile Function: A Systematic Review and Meta-analysis. Eur Urol. 2017;71:223-233.

13. Angulo JC, Arance I, de Las Heras MM, Meilán E, Esquinas C, Andrés EM. Efficacy of low-intensity shock wave therapy for erectile dysfunction: A systematic review and metaanalysis. Actas Urol Esp. 2016. pii:S0210-480630117-6.

14. Moher D, Liberati A, Tetzlaff J, Altman DG; PRISMA Group. Preferred reporting items for systematic reviews and metaanalyses: the PRISMA statement. BMJ. 2009;339:b2535.

15. Higgins JP, Altman DG, Gøtzsche $P C$, Jüni $P$, Moher $D$, Oxman AD, et al. The Cochrane Collaboration's tool for assessing risk of bias in randomised trials. BMJ. 2011;343:d5928.

16. Slim K, Nini E, Forestier D, Kwiatkowski F, Panis Y, Chipponi J. Methodological index for non-randomized studies (minors): development and validation of a new instrument. ANZ J Surg. 2003;73:712-6.

17. Olsen AB, Persiani M, Boie S, Hanna M, Lund L. Can lowintensity extracorporeal shockwave therapy improve erectile dysfunction? A prospective, randomized, double-blind, placebo-controlled study. Scand J Urol. 2015;49:329-33.

18. Yee CH, Chan ES, Hou SS, Ng CF. Extracorporeal shockwave therapy in the treatment of erectile dysfunction: a prospective, randomized, double-blinded, placebo controlled study. Int J Urol. 2014;21:1041-5.

19. Bechara A, Casabé A, De Bonis W, Nazar J. [Effectiveness of low-intensity extracorporeal shock wave therapy on patients with Erectile Dysfunction (ED) who have failed to respond to PDE5i therapy. A pilot study]. Arch Esp Urol. 2015;68:152-60.

20. Chung E, Cartmill R. Evaluation of clinical efficacy, safety and patient satisfaction rate after low-intensity extracorporeal shockwave therapy for the treatment of male erectile dysfunction: an Australian first open-label single-arm prospective clinical trial. BJU Int. 2015;115 (Suppl 5):46-9.

21. Qi T, Wang B, Chen J. Comparison of clinical efficacy on penile erectile dysfunction between extracorporeal shock wave and vacuum erectile device: a randomized controlled clinical trial. J N Med. 2015; 46: 597-9.

22. Pelayo-Nieto M, Linden-Castro E, Alias-Melgar A, EspinosaPérez Grovas D, Carreño-de la Rosa F, Bertrand-Noriega F, et al. Linear shock wave therapy in the treatment of erectile dysfunction. Actas Urol Esp. 2015;39:456-9.

23. Reisman $Y$, Hind A, Varaneckas A, Motil I. Initial experience with linear focused shockwave treatment for erectile dysfunction: a 6-month follow-up pilot study. Int J Impot Res. 2015;27:108-12.
24. Ruffo A, Capece M, Prezioso D, Romeo G, Illiano E, Romis $L$, et al. Safety and efficacy of low intensity shockwave (LISW) treatment in patients with erectile dysfunction. Int Braz J Urol. 2015;41:967-74.

25. Srini VS, Reddy RK, Shultz T, Denes B. Low intensity extracorporeal shockwave therapy for erectile dysfunction: a study in an Indian population. Can J Urol. 2015;22:761422.

26. Hisasue S, China T, Horiuchi A, Kimura M, Saito K, Isotani $S$, et al. Impact of aging and comorbidity on the efficacy of low-intensity shock wave therapy for erectile dysfunction. Int J Urol. 2016;23:80-4.

27. Frey A, Sønksen J, Fode M. Low-intensity extracorporeal shockwave therapy in the treatment of postprostatectomy erectile dysfunction: a pilot study. Scand J Urol. 2016;50:123-7.

28. Kitrey ND, Gruenwald I, Appel B, Shechter A, Massarwa O, Vardi Y. Penile Low Intensity Shock Wave Treatment is Able to Shift PDE5i Nonresponders to Responders: A DoubleBlind, Sham Controlled Study. J Urol. 2016;195:1550-5.

29. Qiu X, Lin G, Xin Z, Ferretti L, Zhang H, Lue TF, et al. Effects of low-energy shockwave therapy on the erectile function and tissue of a diabetic rat model. J Sex Med. 2013;10:738-46.

30. Liu J, Zhou F, Li GY, Wang L, Li HX, Bai GY, et al. Evaluation of the effect of different doses of low energy shock wave therapy on the erectile function of streptozotocin (STZ)induced diabetic rats. Int J Mol Sci. 2013;14:10661-73.

31. Zou ZJ, Liang JY, Lu YP. Re: Zhihua Lu, Guiting Lin, Amanda Reed-Maldonado, Chunxi Wang, Yung-Chin Lee, Tom F. Lue. Low-intensity Extracorporeal Shock Wave Treatment Improves Erectile Function: A Systematic Review and Meta-analysis. Eur Urol 2017;71:223-33. Eur Urol. 2017;71:e57-e58.

32. Gao L, Qian S, Tang Z, Li J, Yuan J. A meta-analysis of extracorporeal shock wave therapy for Peyronie's disease. Int J Impot Res. 2016;28:161-6.

33. Vardi Y, Appel B, Kitrey ND, et al. Additional shockwave treatment improves erectile function in patients with poor response to the standard shockwave protocol. Eur Urol Suppl. 2014; 13: e604.

34. Müller A, Akin-Olugbade $\mathrm{Y}$, Deveci S, Donohue JF, Tal R, Kobylarz KA, et al. The impact of shock wave therapy at varied energy and dose levels on functional and structural changes in erectile tissue. Eur Urol. 2008;53:635-42.

35. Fode M, Albersen M. Re: Zhihua Lu, Guiting Lin, Amanda Reed-Maldonado, Chunxi Wang, Yung-Chin Lee, Tom F. Lue. Low-intensity Extracorporeal Shock Wave Treatment Improves Erectile Function: A Systematic Review and Meta-analysis. Eur Urol 2017;71:223-33. Eur Urol. 2017;71:e76-e77. 
36. Rosen RC, Allen KR, Ni X, Araujo AB. Minimal clinically important differences in the erectile function domain of the International Index of Erectile Function scale. Eur Urol. 2011;60:1010-6.

37. Vardi Y, Appel B, Kitrey N, et al. Low-intensity shockwave treatment for ED-long term follow up of 2 year. Eur Urol Suppl. 2014;13: e603.

38. Wang CJ, Huang HY, Pai CH. Shock wave-enhanced neovascularization at the tendon-bone junction: an experiment in dogs. J Foot Ankle Surg. 2002;41:16-22.

39. Inoue $S$, Kurimura $Y$, Sadahide $K$, et al. Low intensity extracorporeal shock wave therapy for erectile dysfunction in ED patients: initial experience in Japan. J Sex Med. 2013;10: 224.

40. Li H, Matheu MP, Sun F, Wang L, Sanford MT, Ning H, et al. Low-energy Shock Wave Therapy Ameliorates Erectile Dysfunction in a Pelvic Neurovascular Injuries Rat Model. J Sex Med. 2016;13:22-32. Erratum in: J Sex Med. 2016;13:732.
41. Jeon SH, Shrestha KR, Kim RY, Jung AR, Park YH, Kwon 0 , et al. Combination Therapy Using Human Adiposederived Stem Cells on the Cavernous Nerve and Lowenergy Shockwaves on the Corpus Cavernosum in a Rat Model of Post-prostatectomy Erectile Dysfunction. Urology. 2016;88:226.e1-9.

Correspondence address: Rui Gao, MD, PhD Department of Urology The First Affiliated Hospital of Fujian Medical University, 20 Chazhong road, Fuzhou, Fujian 350005, P.R. China. Telephone: + 86028 8542-2444 E-mail: fyyyruigao@163.com 